\title{
The Journal de l'École polytechnique, A Revival
}

\section{Claude Sabbah}

Let us start with an observation. At each stage of a mathematician's academic career, the weight of the publication list in his or her CV continues to increase, as it does for any scientist. With a steady increase in the number of mathematicians, so too is there a rapidly growing number of mathematics publications; in particular, a growing number of publications of high scientific quality. Why complain that the number of mathematical papers is growing? We can be glad for the increase in papers of a very high scientific interest. This phenomenon will continue to develop, whatever good practices are implemented to control it, for the very reason that the financial support of mathematics departments or individual research projects, through grants or promotions, depends so much on the publication list. It is not a matter here of the nature of the assessment, but only of the fact that this assessment is fundamental in the decision process for funding.

Big commercial publishers, who publish a large number of mathematical journals, therefore play an essential, while implicit, role in the decision

Claude Sabbah is director of research at CNRS at École Polytechnique, France. His email address is Claude. Sabbah@math. polytechnique. fr.

Many thanks to Thierry Bouche, as well as John Ball, Phil Boalch and Carlos T. Simpson, who helped me to improve this article.

Members of the Editorial Board for Scripta Manent are: Jon Borwein, Thierry Bouche, John Ewing, Andrew Odlyzko, Ann Okerson.

DOI: http://dx.doi.org/10.1090/noti1151
Let's just do it. Robert Rosebrugh Scripta Manent, Notices of the AMS, January 2013

processes for funding, by providing a concrete basis for the assessment of the publication lists.

The Gold Open Access model with author processing charges (APC) generates small business structures, many of them being considered as "predatory publishers," which absorb part of the mathematics literature. They promise quick publication and low APC but they do not, for the most part, ensure long-term archiving. Such structures develop purely commercial techniques to attract authors and to increase their income. In such a model, the author publishes his/her article as if he/she were publishing a classified ad.

The development of electronic academic journals comes as a possible answer to the problems raised by this new publishing environment. They can offer at once a high-quality editorial process, assessed by the sponsorship of scientific institutions, and solutions for long-term archiving. Universities will benefit from supporting academic journals through the higher visibility of the mathematical research they develop, in the same way that they may benefit from the massive open online courses they produce. Moreover, the growing acceptance of electronic journals by mathematicians, as readers and more importantly as authors, allows one to forget about the management of subscriptions and printing, a problem which has led many print university journals to entrust their future to commercial publishers. As noted by Ingrid Daubechies [1], president of the International Mathematical Union: "Electronic publishing is potentially a great game changer." 
The university journals may find it advantageous to join together, while remaining independent from each other, by forming small structures supported by renowned academic institutions (learned societies, research agencies, national or international research institutions) in order to share effective tools for the management of the editorial and publishing process and the dissemination and archiving of electronic articles. A few such structures have already been developed in the US (Project Euclid, IMS, MSP), but this model is not developed enough in Europe, possibly because of the strength of commercial publishers and the existence of many learned societies of various sizes. Developing small production-dissemination-archiving structures, supported by academic institutions, will provide electronic university journals with a secure environment without profitability constraints. For example, ensuring quick publication cannot be emphasized as a quality feature, if it compromises a rigorous refereeing process. Increasing the number of pages published by existing academic journals or creating new electronic academic journals may thus offset the rapid expansion of low-cost and low-quality journals.

Let me quote Ingrid Daubechies once more: "Emancipation of our journals: Set our journals free!" Support by academic institutions will provide for most of the funding needs of an electronic journal through hosting a website with editorial management and electronic edition, and possibly copyediting of the articles. In such a way, the APC may be approached differently. Institutions may sponsor small publishing structures by funding part of their needs. The example of arXiv shows that this is possible. Various institutions were concerned with the question of permanent electronic archiving. They may as well be concerned with supporting structures which foster the development of productive academic journals.

At the École Polytechnique, fondly known as "l'X" by the cognoscenti for the two crossed swords of its insignia, the more favorable conditions offered by the growing acceptance of electronic publications in the mathematical community, allowing the elimination of most of the flow of money, together with the increasing cost of the mathematical literature, urged us to add our modest contribution to the strategy of developing academic publications: The new electronic mathematical journal entitled Journal de l'École polytechnique-Mathématiques (JEPM) [5] has been launched recently on the basis of "diamond" open access (free access and no APC). A Creative Commons license is proposed to authors.

The Journal de l'École polytechnique, a scientific journal launched in 1795 during the French Revolution just after the creation of the École
Polytechnique, was published more or less regularly until 1939, and the memory of its existence is now safely kept by Gallica [4], at the French National Library. Most of the important French mathematicians of the nineteenth century have been authors of articles in this journal, which also published articles of other scientists. Primarily aimed at promoting research results obtained by professors and students of the École Polytechnique, it also published series of lectures provided there by teachers like Monge and Prony, and lectures provided by Lagrange and Laplace at the École Normale Supérieure, created around the same time. The celebrated article Analysis situs by Poincaré was published in the centenary issue (1895). But a narrow editorial policy led to its extinction at the beginning of World War II.

Our principal strengths to convince mathematicians that we focus on a high quality for all aspects of the publication are:

- the prestigious history of the Journal de l'École polytechnique,

- the sponsorship and support of various French research institutions.

The composition of the Editorial Board reflects our choice to cover a wide spectrum from applied to fundamental mathematics, in the continuation of the Journal de l'École polytechnique. Let me emphasize that we feel it important to continue creating general mathematical journals where various mathematical communities can find common interest for publication.

How does it work? The Centre national de la recherche scientifique (CNRS) (the big French research agency composed of various thematic institutes), through its institute dedicated to mathematics (National Institute for Mathematical Sciences [6]), provides support to various academic journals, among which is the JEPM, in two complementary ways:

- The "Centre de diffusion de revues académiques mathématiques" (cedram) [2] provides the journals with complete support concerning electronic production and dissemination, and archiving in the numdam database [8].

. The "Mathrice" network [7] offers an implementation of the Open Journal System provided by the Public Knowledge Project [9] dedicated to online submission to journals and article management.

This support reduces the financial needs for copyediting and typesetting, and is efficiently complemented with the support of École Polytechnique through its staff and its publishing house, which will provide a few printed volumes of the JEPM. These volumes will serve for archiving the journal in a printed form and will be sold to libraries at a reasonable cost. 


\section{GHzürich}

\section{Assistant Professor of Mathematics}

$\rightarrow$ The Department of Mathematics at ETH Zurich www.math.ethz.ch invites applications for an assistant professor position in mathematics (non-tenure track).

$\rightarrow$ Candidates should hold a PhD or equivalent and have demonstrated the ability to carry out independent research work. Willingness to teach at all university levels and to participate in collaborative work within or outside the school is expected. The new professor will be expected to teach undergraduate (in German or English) and graduate courses (in English) for students of mathematics, natural sciences and engineering.

$\rightarrow$ Assistant professorships have been established to promote the careers of younger scientists.

The initial appointment is for four years with the possibility of extension to six years.

$\rightarrow$ Please apply online at

www.facultyaffairs.ethz.ch

$\rightarrow$ Applications should include a curriculum vitae, a list of publications, and a statement of future research and teaching interests. The letter of application should be addressed to the President of ETH Zurich, Prof. Dr. Ralph Eichler. The closing date for applications is 30 September 2014.

ETH Zurich is an equal opportunity and family friendly employer and is further responsive to the needs of dual career couples.

We specifically encourage women to apply.
Our editorial project aims at contributing to the strategy of developing academic electronic mathematical journals. We feel it to be important that these journals can join together in relatively small institutional entities that furnish common technical support for the editorial and archiving aspects, as opposed to academic journals managed by big commercial publishers. Alternatives to feebased Open Access are possible for mathematical publications, and will not lead to increasing the commercial aspects of scientific publications.

\section{References}

[1] INGRID DAUBECHIES, IMU Blog on mathematics, Oct. 25, 2012,http://blog.mathunion.org/rating/

[2] cedram:/http://www. cedram.org

[3] Ecole Polytechnique: http://www.polytechnique. edu/

[4] Journal de l'École polytechnique: http://ga11ica.bnf. fr/ark: /12148/cb34378280v/date

[5] Journal de l'École polytechnique-Mathématiques: http://jep.cedram.org

[6] INSMI:/http://www.cnrs.fr/insmi/

[7] Mathrice: network of computer engineers in the mathematics laboratories of the CNRS, http://www.mathrice.org/

[8] numdam: a repository for publications in mathematics, http://www. numdam.org

[9] PKP: "The Public Knowledge Project is a research and development initiative directed toward improving the scholarly and public quality of academic research through the development of innovative online publishing and knowledge-sharing environments. It is located at the University of British Columbia, Simon Fraser University, Stanford University, and Arizona State University," http://pkp.sfu.ca 